\title{
Nitrous oxide cooling in hybrid rocket nozzles
}

\author{
Patrick Lemieux \\ California Polytechnic State University, San Luis Obispo, CA 93407, United States
}

\begin{abstract}
A B S T R A C T
The Department of Mechanical Engineering at the California Polytechnic State University, San Luis Obispo, has developed an innovative program of experimental research and development on hybrid rocket motors (where the fuel and the oxidizer are in different phases prior to combustion). One project currently underway involves the development of aerospike nozzles for such motors. These nozzles, however, are even more susceptible to throat ablation than regular converging diverging nozzles, due the nature of their flow expansion mechanism. This paper presents the result of a recent development project focused on reducing throat ablation in hybrid rocket motor nozzles. Although the method is specifically targeted at increasing the life and operating range of aerospike nozzles, this paper describes its proof of concept implementation on conventional nozzles. The method is based on a regenerative cooling mechanism that differs in practice from that used in liquid propellant motors. A series of experimental tests demonstrate that this new method is not only effective at reducing damage in the most ablative region of the nozzle, but that the nozzle can survive multiple test runs.
\end{abstract}

\section{Contents}

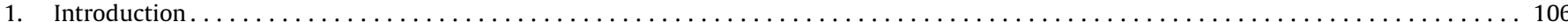

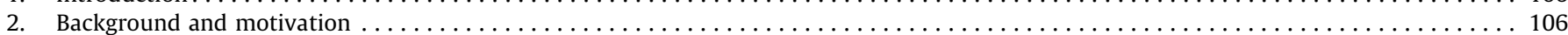

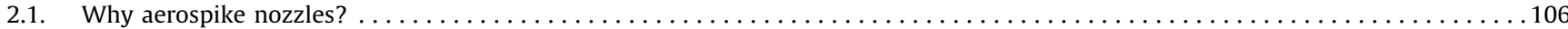

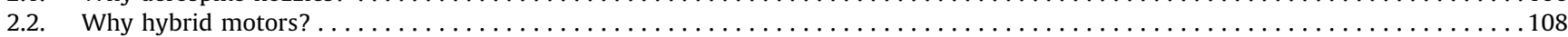

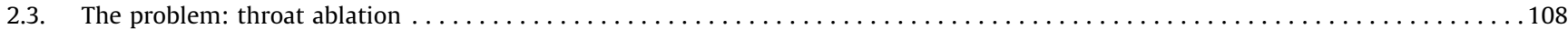

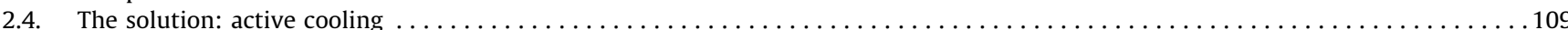

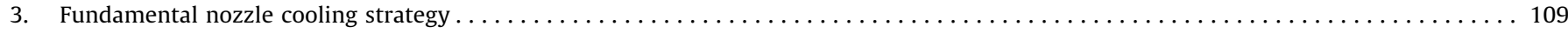

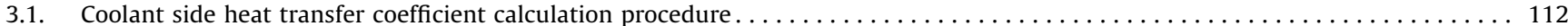

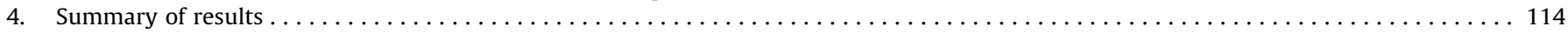

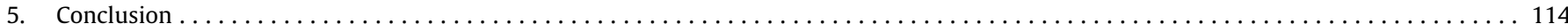

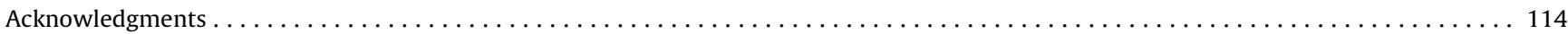

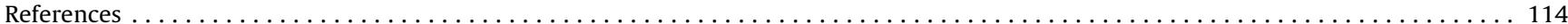

\section{Introduction}

Over the past five years, the Department of Mechanical Engineering at the California Polytechnic State University, San Luis Obispo (Cal Poly) has been developing a facility for the ultimate goal of designing and testing aerospike nozzles on hybrid rocket motors. The present state of this work includes a small hybrid rocket motor test stand capable of measuring hot fired tests of conventional nozzles with axial thrusts upward of $7001 b_{f}$, and vectored thrust of up to $100 \mathrm{l} \mathrm{b}_{\mathrm{f}}$. The test stand also supports cold flow tests.
One of the difficulties with hot fired aerospike nozzles, however, is the high heat loads at the base of the spike, which can cause ablation of the spike and a degradation of performance, and eventually even cause failure of the entire nozzle and rocket. The study presented here looks at a novel way to mitigate the high heat loads in a hybrid rocket motor nozzle, and presents the result of a study conducted to test the concept.

\section{Background and motivation}

\subsection{Why aerospike nozzles?}

The purpose of a rocket motor nozzle is to accelerate a propellant, from a reservoir at high stagnation pressure, for the 


\begin{tabular}{|llll|}
\hline \multicolumn{2}{|l}{ Nomenclature } & $P_{e}$ & exit plane pressure \\
& & $P_{0}$ & nozzle stagnation pressure \\
$A_{e}$ & nozzle exit plane area & $P_{\infty}$ & ambient pressure \\
$A^{*}$ & nozzle throat area & $P r$ & Prandtl number \\
$C$ & constant (dimensionless) & $R$ & axial radius of curvature of nozzle \\
$C_{F}$ & thrust coefficient & $R e$ & Reynolds number \\
$D_{t}$ & throat diameter & $T_{c o o l}$ & measured coolant temperature \\
$h$ & local heat transfer coefficient & $T_{c u}$ & measured copper throat temperature (cold side) \\
$I_{s p}$ & specific impulse & $z$ & axial distance along nozzle \\
$N u$ & Nusselt number & $\gamma$ & ratio of specific heats \\
& & & \\
\hline
\end{tabular}

purpose of creating thrust. The 'effectiveness' with which it produces thrust is generally characterized by the nozzle thrust coefficient, which is the thrust normalized by the product of throat area and nozzle stagnation pressure. Considering the case of a rocket motor powered by a calorically perfect gas expanding through a nozzle, Eq. (1) expresses its thrust coefficient as a function of operating parameters and ambient pressure into which the nozzle discharges.

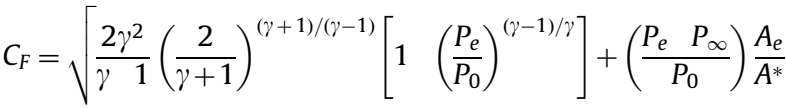

It can be shown that the nozzle performance, as characterized by the thrust coefficient, is maximized when the nozzle operates at fully expanded conditions, i.e., when the nozzle exit plane pressure equals the ambient pressure, a condition that defines the nozzle's design pressure ratio $P_{0} / P_{\infty}$. For a conventional conver ging diverging nozzle, with fixed area ratio, this means that performance can only be optimum at a single operating ambient pressure. For the continuously changing ambient pressure (and thus nozzle pressure ratio) of a typical rocket atmospheric trajectory, the thrust coefficient is therefore non optimum for much of its operation. The effect of this change in nozzle performance as a function of altitude can be seen in Fig. 1, where the overexpanded flow condition of the nozzle is clearly evident in the shape of the plume at sea level, in contrast to its operation at high altitude, closer to its design pressure ratio.

The 'aerospike' nozzle, by contrast, consists of a shaped longitudinal spike protruding past the body of the motor, creating an annular throat at the plane where it protrudes, and directing the flow radially inwards along the spike. The propellant gases then expand outside the engine, along the spike, which may be thought of as consisting of an infinite series of 'ramps' for the flow to realign itself longitudinally. There are no physical outside boundaries to the nozzle, so the plume is immediately at atmo spheric pressure. The contour is effectively that of a conventional converging diverging nozzle turned 'inside out', and much of the same design methods apply. Fig. 2 shows an aerospike nozzle designed at Cal Poly and used in our cold flow facility for demonstration and flow visualization purposes. It uses com pressed air as a propellant.

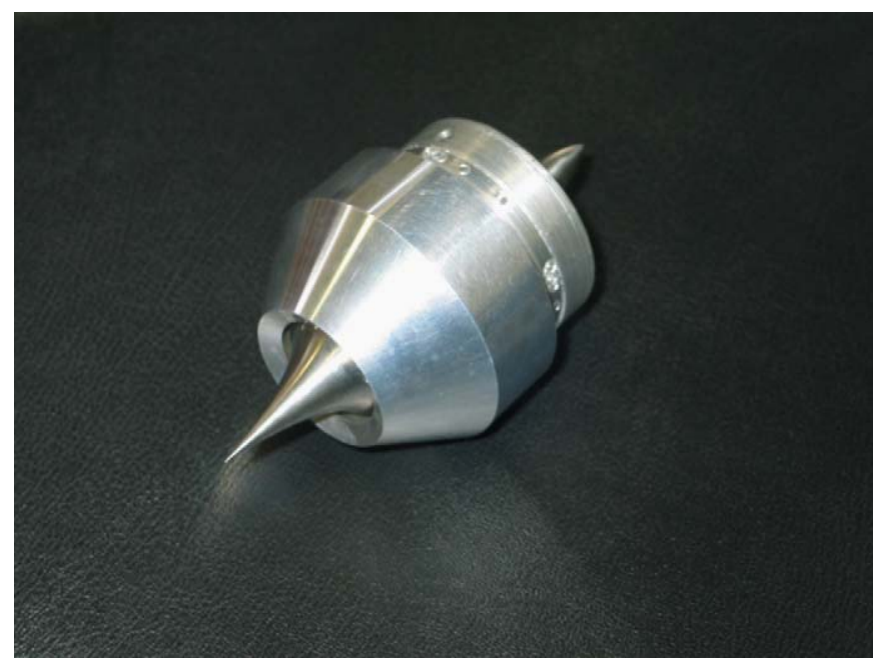

Fig. 2. Cal Poly's aerospike nozzle, used for cold flow tests.
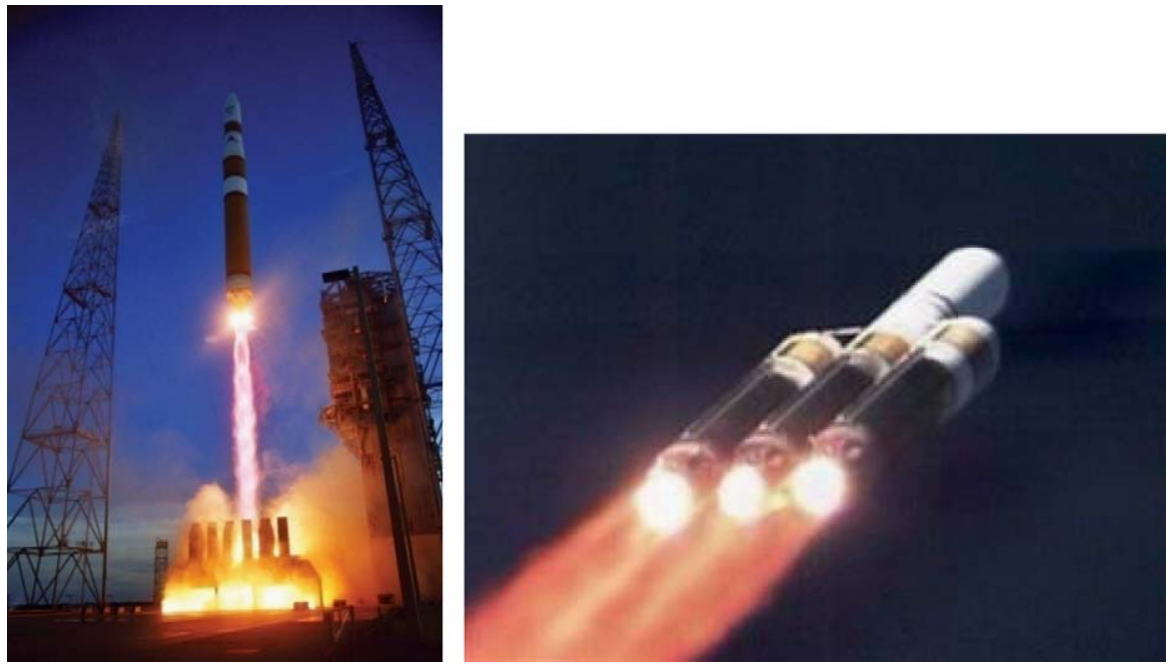

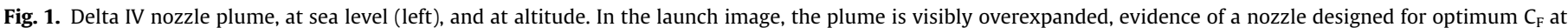
much higher altitudes [1]. 


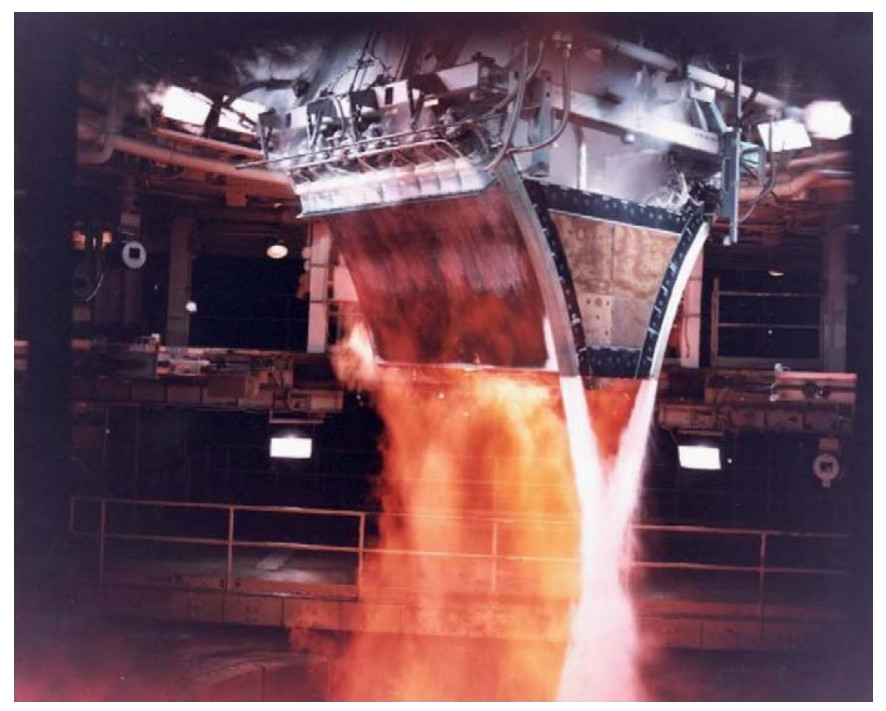

Fig. 3. X-33 truncated linear aerospike, during hot-fire test [4].

During normal operation, the aerospike nozzle works by combining two effects:

1. the axial thrust of the propellant gases at the throat, and

2 . the axial reaction force along the spike.

The unique feature of this design is that at low altitude (lower nozzle pressure ratios), the flow recompresses along the spike in a series of oblique shocks, building pressure continuously on the spike. As the pressure ratio increases (as the rocket gains altitude), the recompression points move axially outward along the spike, causing a natural change in pressure distribution and effectively creating continuous altitude correction of the nozzle. The overall effect is a relatively uniform, longitudinal flow that is parallel to the axis of the engine at all points of flight, approximating an ideally expanded converging diverging nozzle at all nozzle pressure ratios [2]. In terms of performance, Eq. (1) for the thrust coefficient still applies, except that the exit plane pressure, $P_{e}$, now equals the ambient pressure $P_{\infty}$ at all points of flight, and the second term vanishes at every point. The practical benefit of this may best be appreciated by considering an example loosely based on the Delta IV RS 68 rocket motor shown in Fig. 1: consider a converging diverging nozzle with an area ratio of 27 and a chamber pressure of $11 \mathrm{MPa}$, designed for fully expanded operation at $10,000 \mathrm{~m}$. The same rocket motor would then see an increase in thrust coefficient of more than $5 \%$ at sea level if it were fitted with an aerospike nozzle, assuming everything else remained unchanged.

This makes the concept particularly attractive for single stage to orbit missions, where a single nozzle must operate efficiently over a wide range of conditions. The concept works (with reduced effectiveness) even if the spike is truncated, a configuration referred to as plug nozzle. Performance is partly recovered if a gas is injected at the base of the plug ('base bleed'). Perhaps the best known documented development program of such an aerospike nozzle was the one carried out for the X 33 Reusable Launch Vehicle (see Fig. 3). That program, however, was cancelled in 2001 , no doubt due in part to the difficulties of engineering such a new engine.

There is little evidence of test flight data of aerospike motors of any type in the literature. One of the few describes a series of tests on solid rockets, benchmarked against a conventional nozzle [3]. In this test program, two aerospike rockets and one conventional rocket were flown successfully to supersonic speeds, providing the first recorded flights of solid propellant aerospike rockets as well as the first set of transonic flight performance data for these types of rocket motors. To the author's knowledge, there have been no test flights and no published studies of aerospike nozzles on hybrid rocket motors. The lack of a comprehensive flight test database has precluded the use of these types of nozzles in current as well as next generation space vehicles.

Some of the significant drawbacks of aerospikes include the design of a support structure isolated from the heat of the combustion chamber, and the fundamental problem of creating the spike itself so that it can survive and function fully while immersed in the hottest part of the flow.

\subsection{Why hybrid motors?}

Hybrid rocket motors define a class of rocket propulsion systems where the fuel and the oxidizer are introduced in different phases. Most often, fuels are made of a solid 'grain', and the oxidizer is introduced as a liquid; common hybrid rocket motor fuels are $\mathrm{HTPB}^{2}$ and Plexiglas ${ }^{\mathbb{R}}$; a common oxidizer is nitrous oxide $\left(\mathrm{N}_{2} \mathrm{O}\right)$. Advantages of this type of propulsion platform include the convenience of being able to store the fuel and oxidizer in relative safety without special precautions. They do not burn when brought together without a significant source of heat for ignition. Because of its high vapor pressure, $\mathrm{N}_{2} \mathrm{O}$ can be self pumping, thereby reducing the need for expensive designs requiring turbo pumps. It also offers the potential for in flight throttling, shutdown, and re ignition.

The potential for hybrid rocket motors was clearly demon strated in 2004, when SpaceShipOne won the Ansari X Prize using an air launched space vehicle powered by an $\mathrm{N}_{2} \mathrm{O}$ HTPB hybrid rocket motor [5]. On July 26, 2007, a fatal accident during a cold flow test of a hybrid rocket liquid oxidizer at the same company cast doubts over the safety of hybrid motors, their future development, and highlighted the continuing lack of engineering experience with these types of systems. In the future, however, hybrid rocket motors equipped with advanced nozzles with thrust vectoring and throttling capabilities could play a role in programs trying to achieve lower cost access to low earth orbit for NASA and the commercial sector, as well as providing alternative propulsion means for tactical missiles.

The hybrid motor configuration used at Cal Poly can be either polymethyl methacrylate (Plexiglas) or HTPB as fuel (both in a variety of grain configurations), and $\mathrm{N}_{2} \mathrm{O}$ as oxidizer. Different run conditions can be achieved by simply varying the number and size of the $\mathrm{N}_{2} \mathrm{O}$ injectors and by changing the fuel grain geometry. For the purposes of the experiments presented here, a single test condition is used: the fuel consists of a double grain solid (Plexiglas) in annular form, with a cylindrical core of approxi mately 1.75 in in diameter and an outer ring of approximately 2.25 in in inner diameter. The rocket diameter is $4 \mathrm{in}$. The grain is approximately 12 in long. The annular geometry allows for a roughly constant fuel surface area during burn. The oxidizer, nitrous oxide, pressurizes a pre chamber at 200 psi using up to 12 injectors.

\subsection{The problem: throat ablation}

As a result of the environment in which they operate, rocket motors are susceptible to the effect of high heat loads and ablation. Aerospike nozzles are particularly vulnerable to this

\footnotetext{
${ }^{2}$ HTPB is hydroxyl-terminated polybutadiene, a synthetic rubber that is used as a binder in solid rocket motors and as a fuel in hybrid rocket motors.
} 


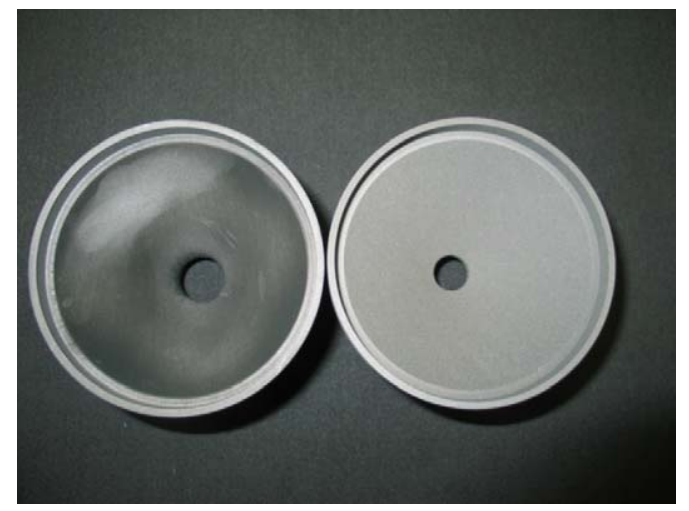

Fig. 4. Converging sections of conventional nozzle graphite liners, used in uncooled, hot-fired tests. The nozzle on the right is new; the one on the left has been fired for approximately $20 \mathrm{~s}$. The severe ablation is evident, as shown by the increased area of the left throat. The thrust peformance of the nozzle degraded continuously throughout the test; the nozzle is un-reusable.

problem, since much of the nozzle is completely surrounded by the hot gas flue. Thus, three options are available to the nozzle developer:

1. Selection of exotic materials, capable of withstanding the highest heat loads expected.

2. Reduction of the maximum heat loads, by limiting chamber pressure or operating the motor at sub optimal oxidizer to fuel ratio.

3. Active cooling of the parts most severely exposed to the hot gases.

Tests conducted at the Cal Poly facility, using conventional nozzles on hybrid motors, have shown that even by lining the nozzle with relatively resistant materials such as graphite, ablation is a difficult (and expensive!) problem to mitigate by material selection alone. Fig. 4 shows the effect of a single 20 second run on the nozzle throat. This translates to continuously degrading thrust performance in the course of a test run. To operate rocket motors in off design modes for the sake of preserving the nozzle does not represent a viable long term solution either. Finally, active cooling of the hottest nozzle surfaces seems to offer the best promise, and has been used for a long time in rocket and gas turbine designs.

\subsection{The solution: active cooling}

Active cooling is a recognized method of maximizing the life and durability of rocket components. Recent published work illustrates how traditional cooling strategies are still applicable to the modern needs of rocket motor designs [ [ 6 8]. These studies, however, traditionally focus on using the fuel to cool engine components.

Using oxidizers for cooling, however, would not appear to be a novel concept. After all, it has been standard procedure for hot section cooling of gas turbine components for many decades, and still represents an area of modern research in that field [9]. The direct use of oxidizers for the cooling of rocket motor components is less prevalent perhaps due to a concern of increased reactivity at the wall. While this potentially increases the engineering complexity of the system development process, it does not impose a fundamental barrier to the use of oxidizers for that purpose.

There are several reasons why $\mathrm{N}_{2} \mathrm{O}$ represents an attractive coolant for component cooling and a few others why it does not.
Unlike most liquid rocket fuels used for active cooling, $\mathrm{N}_{2} \mathrm{O}$ as used in this application is sub critical, meaning that nucleate boiling and the latent heat of vaporization are available to increase heat transfer rates [10]. Because the $\mathrm{N}_{2} \mathrm{O}$ is in a saturated state during the cooling process, its bulk temperature is relatively constant, so that forced convection with the hot walls is enhanced. Finally, because of the saturated state of the $\mathrm{N}_{2} \mathrm{O}$, its pressure can remain relatively constant during the cooling process (provided that the flow speeds are low), so that the system is effectively self pumping, simplifying the setup.

On the other hand, $\mathrm{N}_{2} \mathrm{O}$ dissociates exothermically, so that using it as a coolant creates a risk of runaway reaction that may quickly degenerate into the catastrophic failure of the nozzle. While a true regenerative cooling setup is conceivable (especially in view of the self pumping nature of this coolant), the positive heat of formation of $\mathrm{N}_{2} \mathrm{O}$ (approximately $1.85 \mathrm{~kJ} / \mathrm{kg}$ ), makes it impractical from a safety point of view, and was not developed in this particular experiment. The heated coolant was released outside of the combustion chamber after cooling the throat. In this case, therefore, using this oxidizer reduces the specific impulse of the entire rocket motor in proportion to the mass flow rate used for cooling.

\section{Fundamental nozzle cooling strategy}

\section{Basic contoured nozzle design}

Ablation at the throat is a direct consequence of high localized heat transfer rates and surface temperature. Thus, ablation may be partly mitigated by reducing the coefficient of heat transfer between the hot gases and the nozzle walls. According to Bartz [11], the heat transfer coefficient at the throat is inversely proportional to the radius of curvature at the throat raised to a power, namely

$h \propto \frac{1}{R^{0.1}}$

The radius of curvature at the throat clearly cannot be increased arbitrarily without affecting the overall flow through the nozzle and, eventually, the performance of the rocket motor itself. A rule of thumb in rocket nozzle design is to maintain the circular arc radius of curvature at the throat between 0.5 and 1.5 times the throat radius [12]. Thus, a nozzle consisting of a throat with a large circular arc curvature designed in such a way that it blends the converging conical design upstream to the diverging conical design downstream, matching the nozzle sections used in uncooled tests provides a good starting platform for an actively cooled nozzle designed to be used multiple times. Adapted with a cooling annulus ring around the narrowest part of the throat, the resulting nozzle provided the foundation for the cooling analysis and tests performed in this experiment.

2. Expected heat flux rate for test nozzle, and sizing of coolant passages

The heat transfer level on the hot side depends on the nozzle geometry (curvature), and stagnation and freestream conditions. The latter were calculated using a thermo chemical equilibrium calculation of the hot rocket gases and their temperature at the throat, using a well established calculation method [13]. One goal of the analysis was to mitigate wall heating so that maximum wall temperature ranges from 500 to $1000{ }^{\circ} \mathrm{F}$. Methods for calculating hot side heat transfer coefficients in rocket nozzles are well established, and typically stem from correlations based on a Colburn type relation

$\mathrm{Nu}=\mathrm{C} \operatorname{Re}^{0.8} \operatorname{Pr}^{0.34}$

The technique used here follows the specific correlation developed by Bartz [11]. The heat transfer coefficient on the hot 
side of the nozzle thus obtained is then completely specified by the geometry of the nozzle and the flow conditions (see Fig. 5); the maximum heat flux then is a function of wall temperature only. Finally, wall temperature is ultimately determined by the coolant side heat transfer coefficient, for which there is no closed form expression at this time, so the solution to the heat transfer problem that determines the maximum throat wall temperature must be carried out iteratively.

3. Optimum $\mathrm{N}_{2} \mathrm{O}$ cooling strategy

Within a range of heat flux established for the hot side depending on the test flow conditions, the flow conditions on the cold side may be investigated, and targeted to provide the lowest wall temperature possible. The mechanism by which $\mathrm{N}_{2} \mathrm{O}$ is used to reduce the wall temperature is twofold: first, high pressure saturated liquid $\mathrm{N}_{2} \mathrm{O}$ (typically between 700 and $800 \mathrm{psig}$, depending on ambient temperature), normally used for

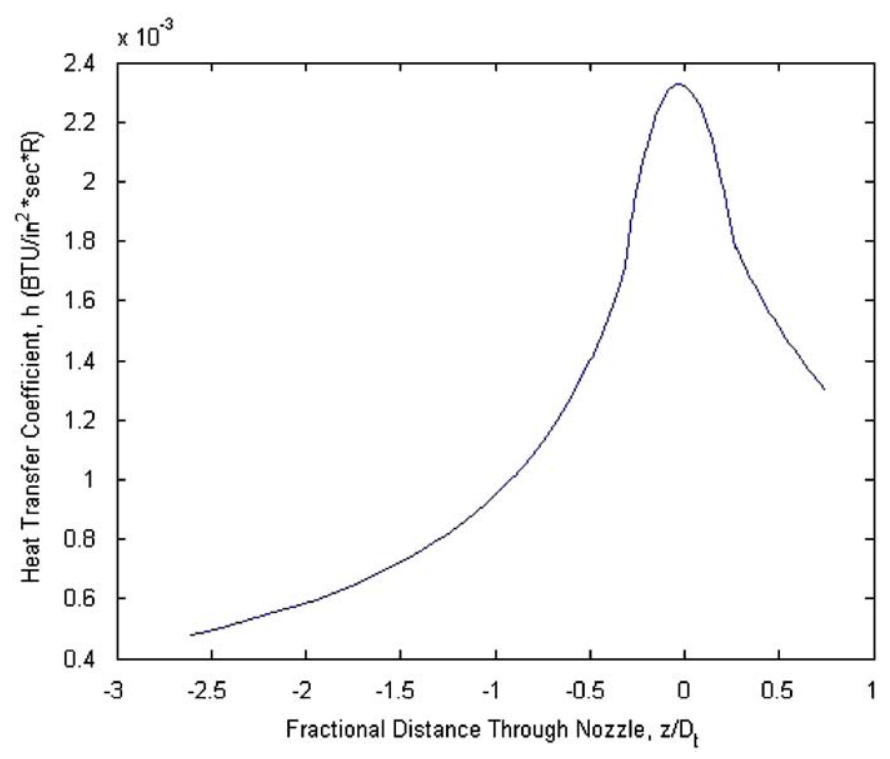

Fig. 5. Calculated heat transfer coefficient, hot side. combustion supply, is re routed to a cooling annulus surrounding the throat, at its highest temperature location. There, it is throttled into the annular ring, at a lower pressure but constant enthalpy. The resultant coolant is thus a two phase liquid vapor mixture and significantly cooler than upstream of the injectors, creating favorable convection conditions for the wall. Second, the two phase coolant continues to evaporate as it flows, at a rate determined by its mass flow rate, latent heat of vaporization and overall heat flux, itself a function of the cold side heat transfer coefficient, surface temperature and area. Nominally, the pressure and temperature of the saturated mixture remains constant while this takes place, though in practice, it appears that localized overheating of the vapor can cause variations in coolant temperature. The continuous heating also causes a drop in pressure, which further tends to reduce saturation temperature. Ideally, from the standpoint of minimizing $I_{s p}$ penalty, the coolant exits the annulus upon reaching its superheated state at that pressure condition.

While this 'cooling strategy' in theory optimizes cooling from the standpoint of minimizing $\mathrm{N}_{2} \mathrm{O}$ use, it also creates a potential risk of exposing superheated coolant to continuing heat flux and thus raising its temperature rapidly, increasing the risk of runaway dissociation. And because of the reduced heat transfer coefficient of single phase vapor, the effectiveness of the cooling setup is also compromised. The conditions at which dissociation occurs are not well understood at this point, and may not be easily predicted. A study of this phenomenon is beyond the scope of the present work, but constitutes an important part of the long term suitability of $\mathrm{N}_{2} \mathrm{O}$ as a coolant in rocket motors of this type.

Based on the shape of the pressure enthalpy $(\mathrm{P} h)$ diagram for $\mathrm{N}_{2} \mathrm{O}$ (see Fig. 6), a suitable target setpoint for the state of the coolant in the annulus is 300 psia. Assuming that the incoming state of the $\mathrm{N}_{2} \mathrm{O}$ is a saturated liquid at 750 psia (corresponding to a bottle temperature of about $70{ }^{\circ} \mathrm{F}$ ), the maximum enthalpy of vaporization available for cooling is approximately $79 \mathrm{BTU} / \mathrm{lb}_{\mathrm{m}}$. This specific heat of vaporization, times the mass flow rate of $\mathrm{N}_{2} \mathrm{O}$ in the cooling passage, is the rate at which heat can be absorbed by the coolant in this scheme.

Implicit in this analysis is that the heat transfer coefficient on the cold side is sufficiently high to maintain the surface

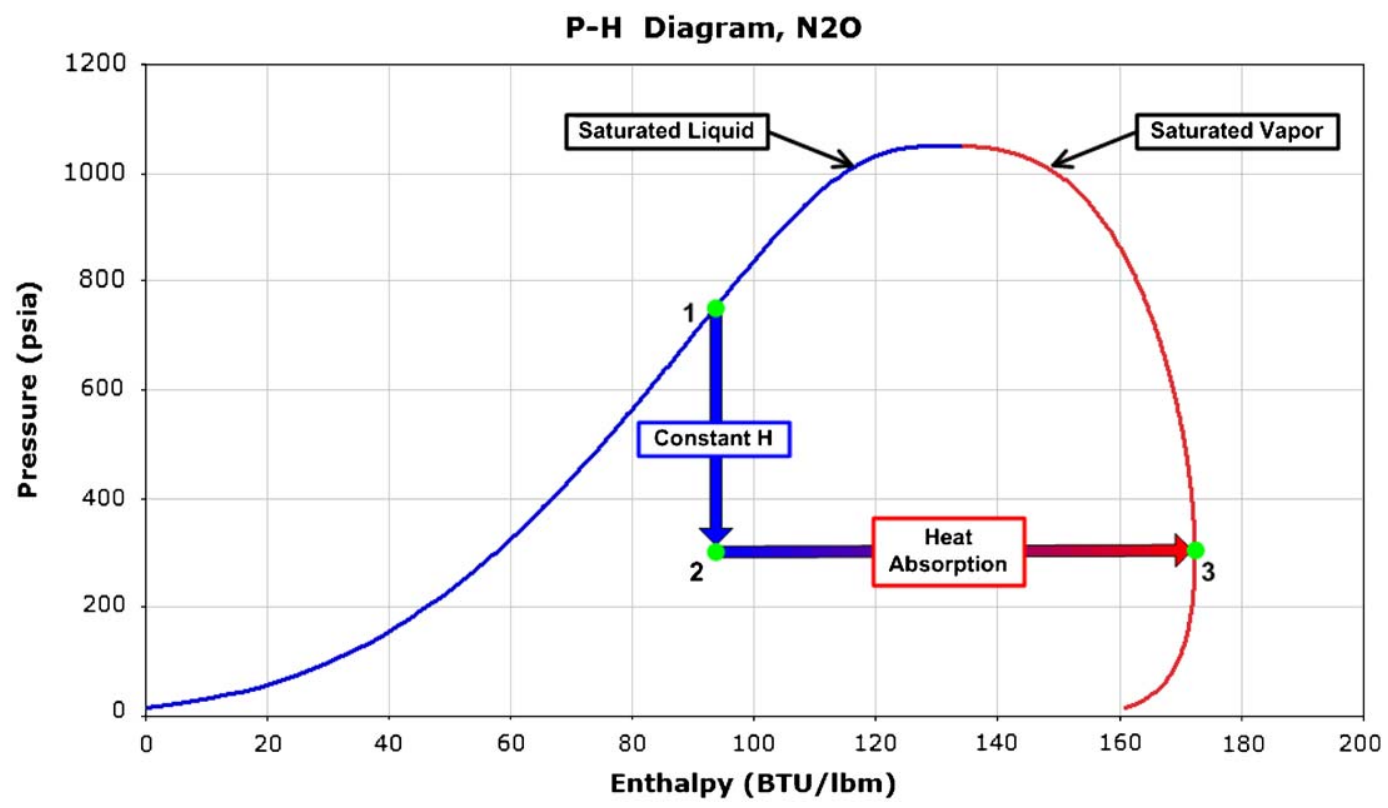

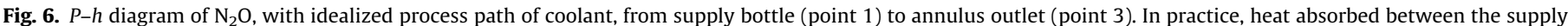
bottle and the annulus injector would shift point 2 to the right, and the pressure may be expected to drop between points 2 and 3 . 


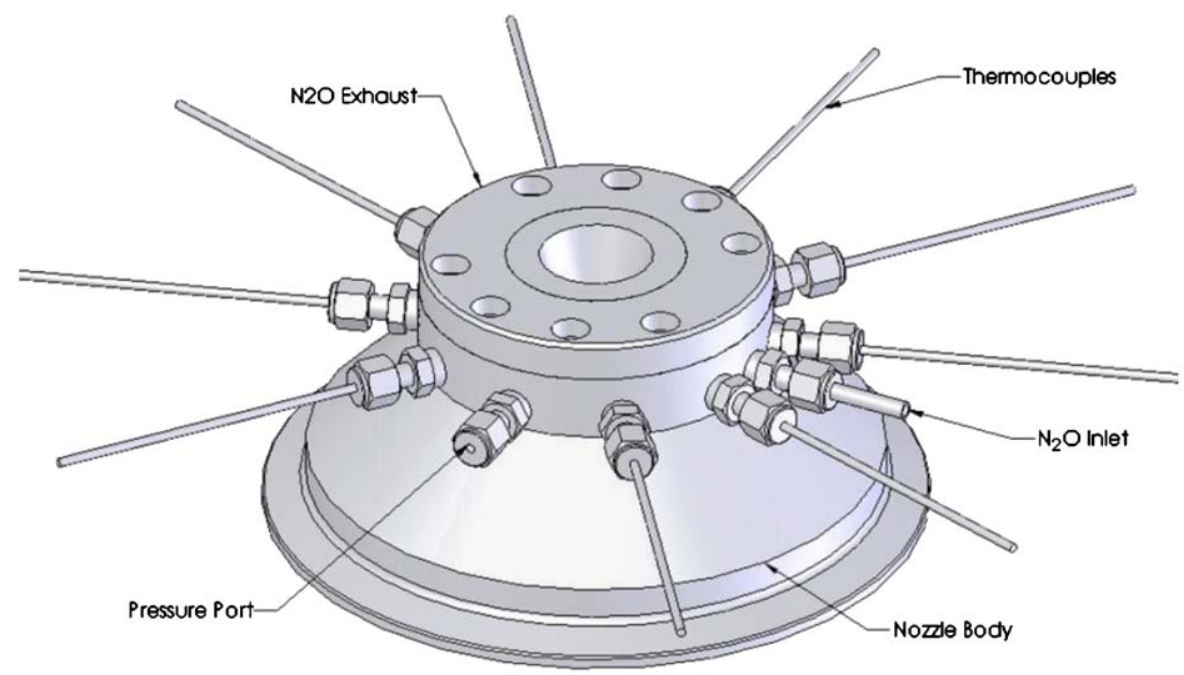

Fig. 7. Design rendering of the single-inlet, single-outlet nozzle.

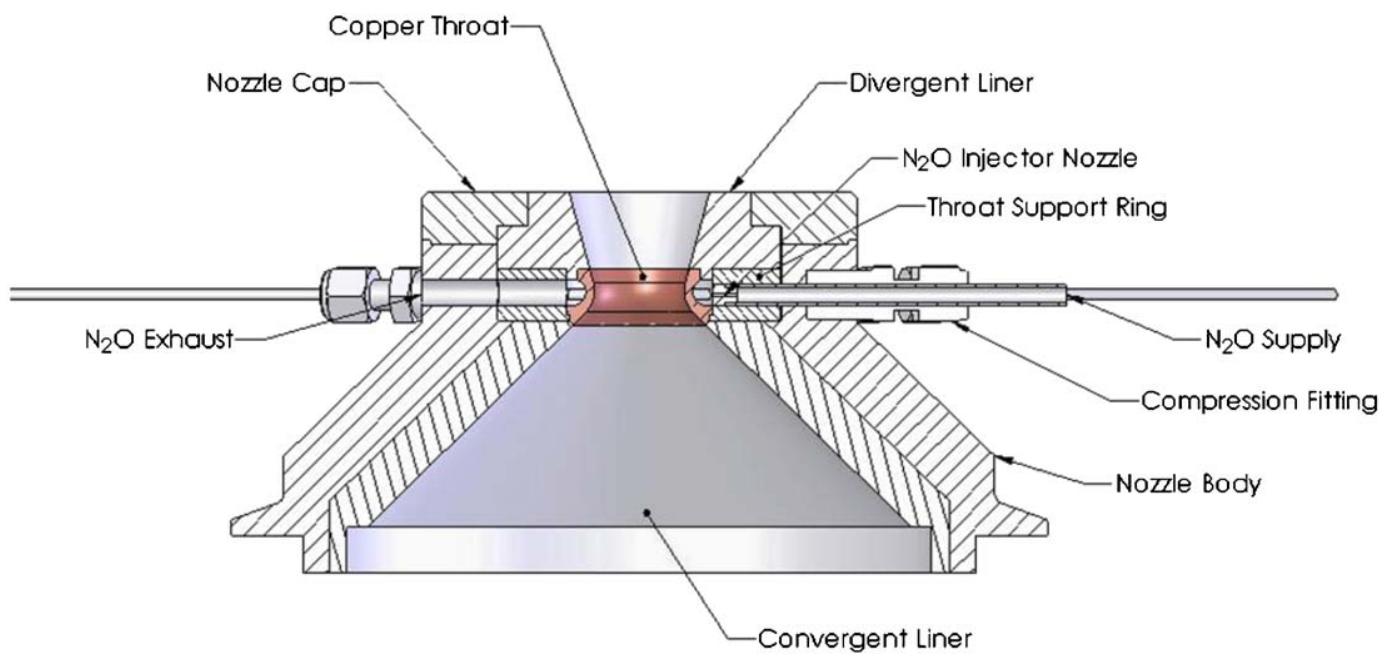

Fig. 8. Cross-sectional view of single-inlet, single-outlet nozzle.

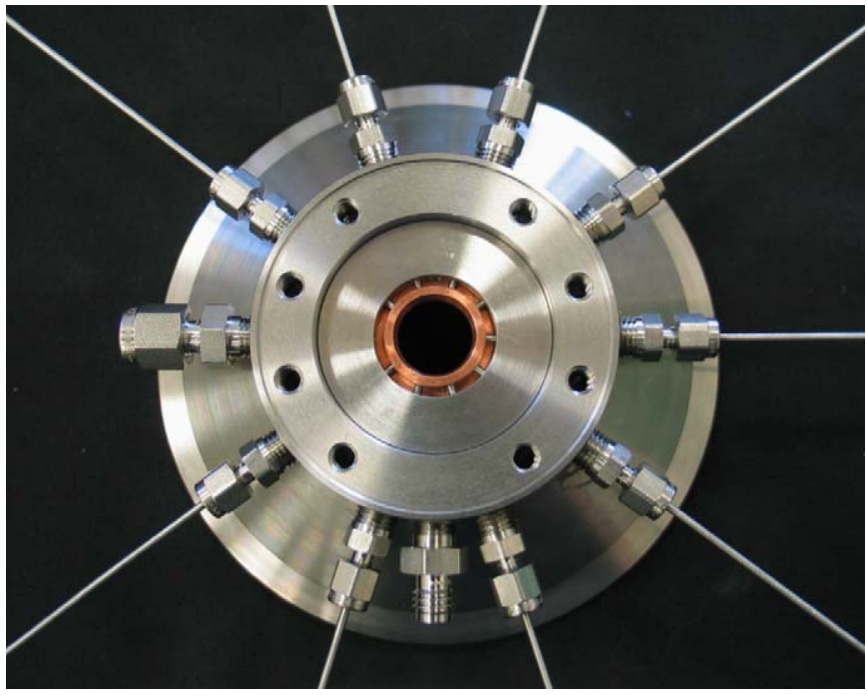

Fig. 9. Nozzle body with the copper throat and thermocouples installed. The downstream conical diverging section is removed, showing the copper throat insert and the cooling annulus. Coolant inlet is at 6 o'clock, pressure tap is at 9 o'clock, and coolant exit (not visible) is at 12 o'clock. temperature at the desired level (at most $1000^{\circ} \mathrm{F}$ ). Since the difference between wall and flow temperatures on the cold side is expected to be approximately 5 times lower than that on the hot side, its average heat transfer coefficient must therefore be 5 times greater than the hot side, assuming that the surface areas exposed to the flows are the same on both sides. If the surface temperature is to be lower, then the ratio of heat transfer coefficients must be correspondingly larger. Similarly, if the surface areas exposed to both flows are not identical, then the required heat transfer coefficients ratio changes accordingly. Furthermore, by energy balance, the higher the flow of coolant in the annulus, the closer point 3 (state of coolant at annulus outlet) remains to point 2 in Fig. 6. With estimates of heat transfer coefficients on the hot and cold sides of the throat along with a target throat surface temperature, a design for the geometry of the cooling passage suitable for the experiment described here is possible.

Heat transfer coefficient calculations for 2 phase, turbulent film boiling, however, are notoriously difficult to perform accurately, and it is generally accepted that the evaluation of this coefficient requires experimental data for most fluids and geometry. This data was not available to us at this point in the project. Qualitatively, the heat transfer coefficient tends to be 
highest when the quality of a two phase flow is in the saturated flow boiling, annular liquid film and vapor core region [14], which is not likely to take place close to the saturated vapor curve, meaning that for a conservative approach, the mass flow rate of

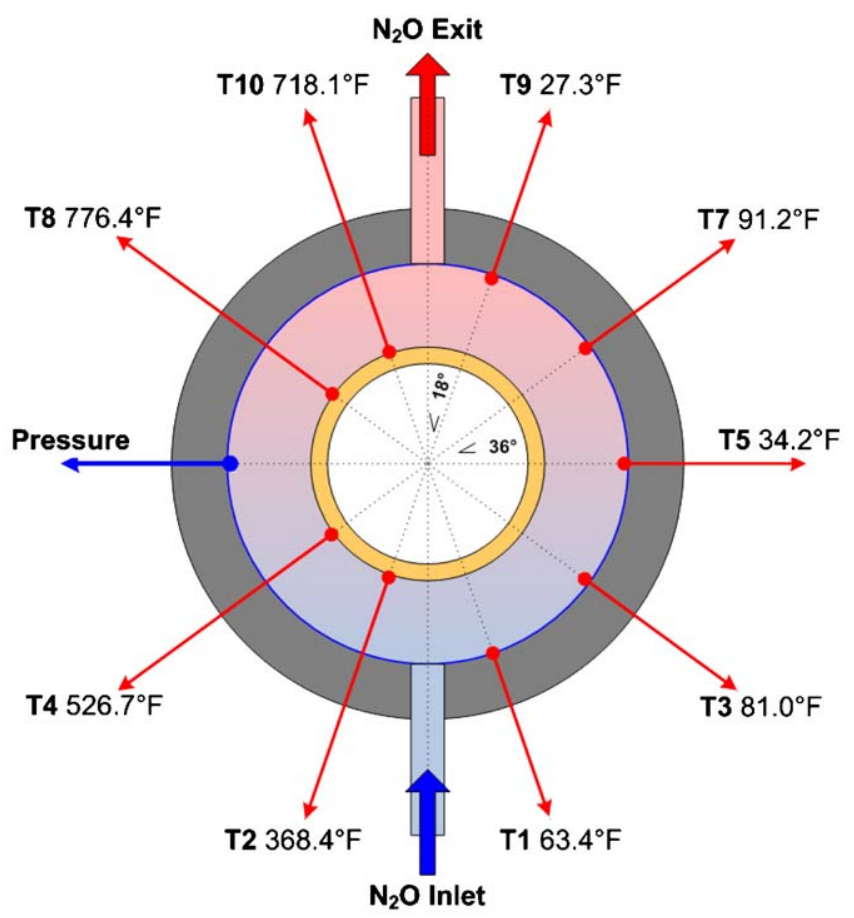

Coolant Flow Channel

Copper Throat

Stainless Steel Housing

Fig. 10. Layout of instruments around the cooling annulus. T1, T3, T5, T7 and T9 measure the bulk coolant temperature; T2, T4, T8, T10 measure the copper throat temperature at its thinnest point. The temperature values shown correspond to a single time point during Run 51. coolant needs to be high enough for the quality of the $\mathrm{N}_{2} \mathrm{O}$ exiting the cooling passage to remain relatively low.

The geometry chosen consists of an annular coolant ring around the throat, with a single inlet and outlet, $180^{\circ}$ apart on the circumference. This geometry provides a means to monitor coolant temperature and pressure, as well as throat temperature, as a function of distance traveled along the cooling passages, with no chance of multiple streams mixing. Thermocouples (for either copper throat surface temperature or coolant bulk temperature) and pressure transducer sensing ports were built in to the apparatus to provide up to ten readings along the cooling paths. The apparatus is presented in Figs. 79.

\subsection{Coolant side heat transfer coefficient calculation procedure}

Through each run, the data for cold side gas temperature, pressure, mass flow rate and surface temperature is continuously recorded. This data, however, does not lend itself directly to a single, overall heat transfer coefficient calculation: first, the transient nature of all runs carried out does not provide good estimates of steady state value of heat transfer coefficient, required in a design focused on a maximum temperature. Next, the material bounding the copper throat participates to some extent in conducting heat to and from the throat, making the actual path of heat transfer three dimensional and difficult to characterize analytically. The temperature profile of the copper throat itself, found to vary significantly along the contour of the annulus, is not easily reduced to a single value representing an 'average convective surface temperature.' Finally, as discussed above, the local heat transfer coefficient changes value continu ously along the cooling path (as the quality of $\mathrm{N}_{2} \mathrm{O}$ increases), and these variations must be taken into account in the overall heat transfer coefficient. Given these limitations, a finite element analysis (FEA) model is ultimately a more appropriate tool to provide detailed design guidelines for such a problem. But the analytical process is nevertheless necessary to provide a starting

Nozzle T.C. Data w/Flow Rate, Annulus Pressure and Chamber Pressure RUN 51

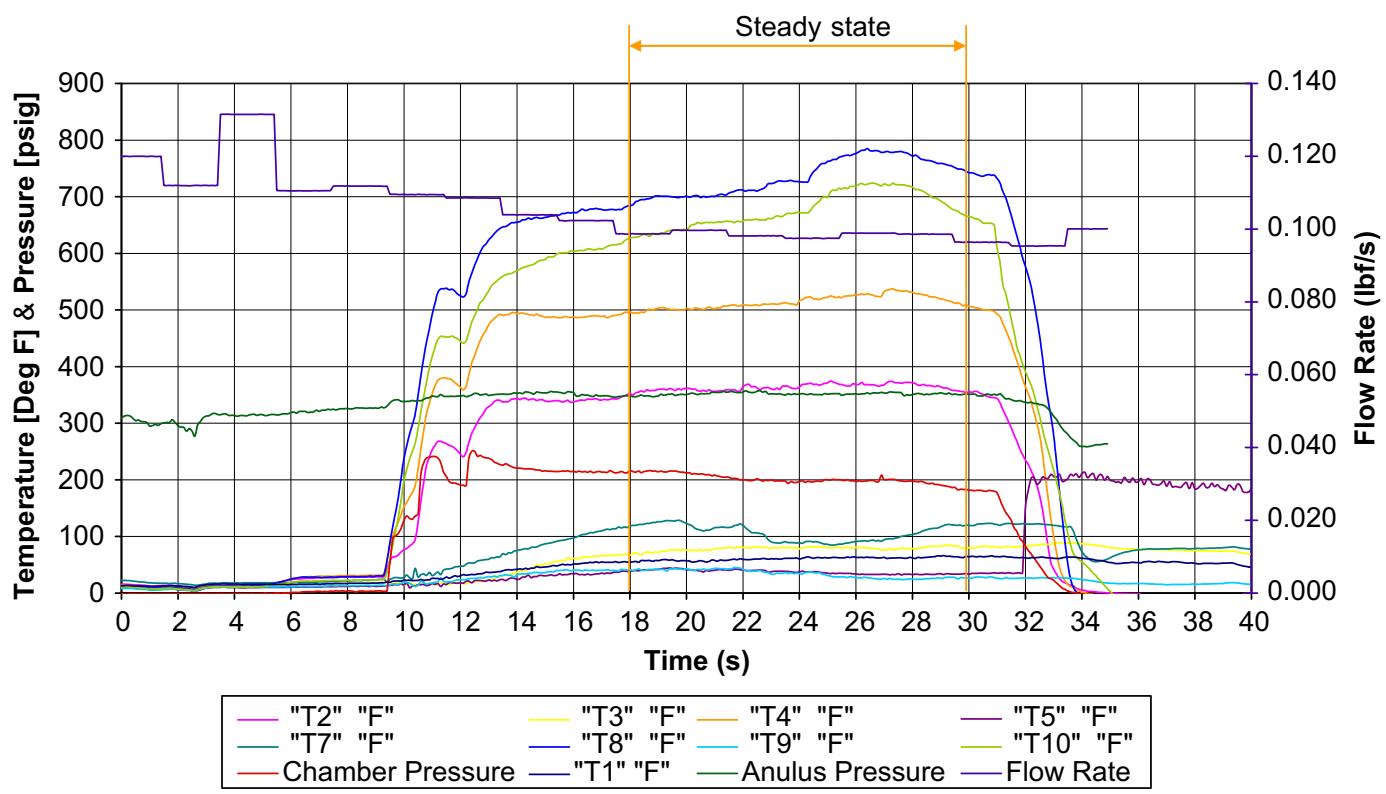

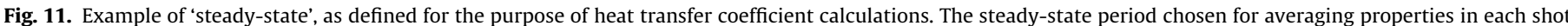
always exceeded $10 \mathrm{~s}$. 
point for finding appropriate boundary conditions to the model, and to troubleshoot its results.

The instrument layout is shown in Fig. 10; the analysis of the experimental results proceeds as follows:

1. While the thermocouple run data appears as a series of transient events, there exists a clear period of steady state operation during each test from the standpoints of coolant pressure, coolant mass flow rate, and rocket chamber pressure (thus rocket operation), see Fig. 11. The heat transfer at the throat during that time is expected to also be relatively constant, and the overall heat transfer coefficient is based on temperature measurements made during that window of time only.

2. The heat transfer process consists of convection from the hot gases to the copper, conduction through the copper, and convection to the coolant. All are assumed to be one dimensional.

3. The carbon sleeve and corrosion resistant steel (CRES) backing of the nozzle body surrounding the copper and cooling passage conduct heat much more slowly that the copper, to both hot and cold sides. For the sake of analysis, these boundaries are assumed to be thermally insulated from the coolant passage and copper throat, i.e., adiabatic boundaries conditions are assumed in all cases (see Fig. 12).

4. Since the heat transfer coefficient is unknown on the cold side, it is unclear how the temperature varies throughout the copper. It is measured at one point, along the throat plane, in the thinnest part of the copper close to the hot flow. The temperature distribution everywhere else on the copper throat may be expected to fall between two extremes:

a. Assume that convective heat transfer (both hot and cold side) is much slower than conductive heat transfer through the copper body: temperature is constant throughout at $T_{\mathrm{cu}}$ (low Biot number assumption, see Fig. 12).

b. Assume that convective heat transfer (both hot and cold side) is much faster than conductive heat transfer through the copper body: copper temperature is uniformly varying, with a gradient between measured $T_{\text {cu }}$ (close to the hot gases at the throat) going down to cool gas temperature at

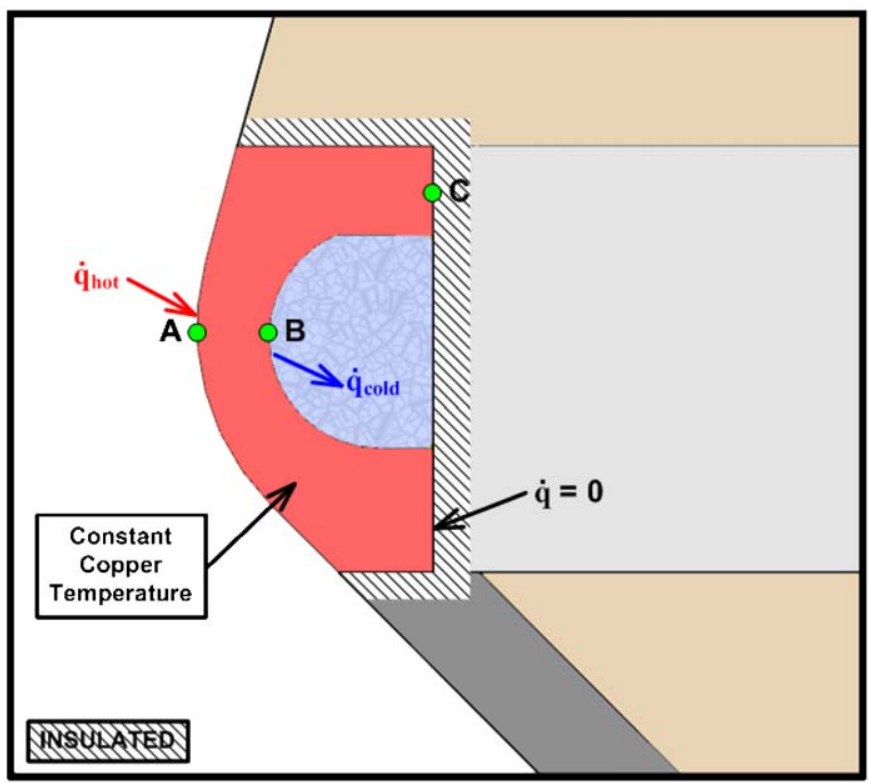

Fig. 12. Low Biot number assumption for heat transfer coefficient calculation.

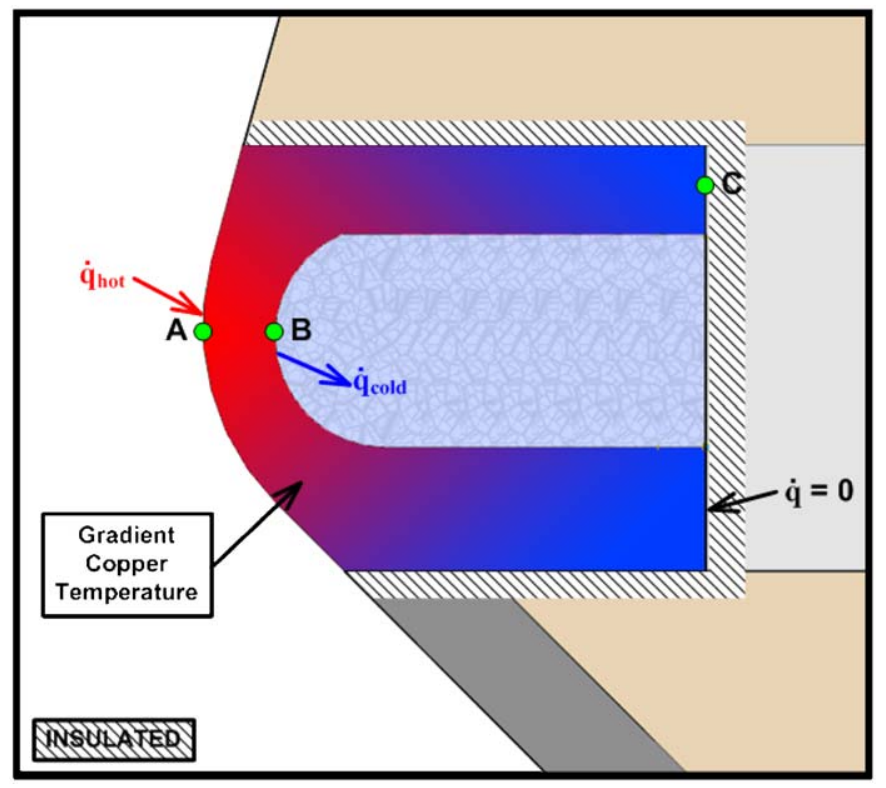

Fig. 13. High Biot number assumption (cold side) for heat transfer coefficient calculation. The size of the copper throat insert is exaggerated for illustration purposes.

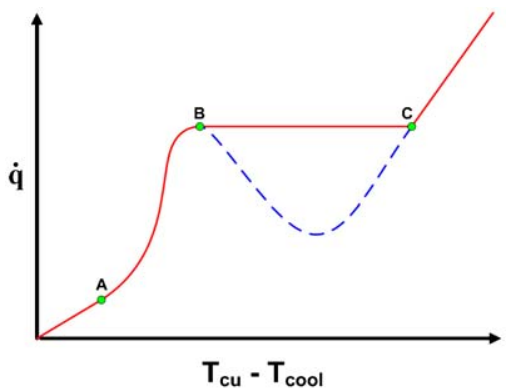

Fig. 14. Heat flux rate as a function of temperature difference between the hot copper surface and coolant temperature for a two-phase coolant (red curve). By contrast, a single phase (or supercritical) coolant heat transfer curve continues rising, more or less linearly, from Point A towards Point $C$, so that two-phase heattransfer coefficients are always higher. The blue dashed-line represents the full boiling curve for a setup where the surface temperature can arbitrarily be changed, typically while going from Point $C$ back towards Point $A$, and is thus not possible in the current application. (For interpretation of the references to colour in this figure legend, the reader is referred to the web version of this article.)

the copper farthest away from the hot gases (high Biot number assumption, cold side, see Fig. 13).

The average, overall heat transfer coefficient may then be directly computed. The heat transfer coefficient used to chara cterize each run is the average of the two coefficients obtained from the two assumptions made in item 4 above.

For two phase flows, the heat transfer rate does not vary linearly with temperature difference with the wall, as it does in the case of a gas. The red curve in Fig. 14 illustrates the typical shape of the heat flux driven boiling curve for two phase flows: heat transfer rates increase rapidly as a function of the difference between the two phase mixture temperature and the surface temperature, up to a maximum at Point B called 'critical heat flux'. The heat flux at that point is sufficiently rapid to cause the continuous flashing of any liquid at the surface, so that the surface is effectively insulated from the core mixture by a layer of vapor. Any increase in heat transfer rate beyond this point requires a 
Table 1

Summary of heat transfer data from NASA cooling runs.

\begin{tabular}{|c|c|c|c|c|c|c|c|c|c|}
\hline \multicolumn{10}{|c|}{ Cooling runs data summary } \\
\hline \multirow[t]{2}{*}{$\begin{array}{l}\text { Run } \\
\#\end{array}$} & \multirow[t]{2}{*}{$\begin{array}{l}\text { Steady-state } \\
\text { Time (sec) }\end{array}$} & \multirow[t]{2}{*}{$\begin{array}{l}\text { Coolant mass flow } \\
\text { rate }(\mathrm{lbm} / \mathrm{sec})\end{array}$} & \multirow[t]{2}{*}{$\begin{array}{l}\text { Coolant } \\
\text { pressure } \\
\text { (PSIG) }\end{array}$} & \multirow[t]{2}{*}{$\begin{array}{l}\text { Average coolant } \\
\text { temperature }(F)\end{array}$} & \multirow[t]{2}{*}{$\begin{array}{l}\text { Average copper } \\
\text { temperature }(F)\end{array}$} & \multirow[t]{2}{*}{$\begin{array}{l}\text { Approx. hot side } \\
\text { temperature (F) }\end{array}$} & \multicolumn{2}{|l|}{$\begin{array}{l}\text { Hot side } \\
\text { average h } \\
\text { BTU }\end{array}$} & \multirow[t]{2}{*}{$\begin{array}{l}\text { Ratio } \\
\text { h_cold/ } \\
\text { h_hot }\end{array}$} \\
\hline & & & & & & & (in $2 * \sec * \mathrm{R}$ & $(\mathrm{in} 2 * \sec * \mathrm{R})$ & \\
\hline 48 & NA & NA & 700 & 70 & NA & 2982 & $2.45 \mathrm{E}-03$ & $5.57 \mathrm{E}-03$ & 2.27 \\
\hline 49 & 10 & 0.059 & 444 & 47 & 435 & 2982 & $2.64 \mathrm{E}-03$ & $1.98 \mathrm{E}-02$ & 7.50 \\
\hline 50 & 15 & 0.048 & 397 & 73 & 563 & 2982 & $2.24 \mathrm{E}-03$ & $1.27 \mathrm{E}-02$ & 5.64 \\
\hline 51 & 12 & 0.1 & 352 & 63 & 573 & 2982 & $2.47 \mathrm{E}-03$ & $1.33 \mathrm{E}-02$ & 5.40 \\
\hline 52 & 12 & 0.05 & 348 & 29 & NA & 2982 & $2.24 \mathrm{E}-03$ & $1.15 \mathrm{E}-02$ & 5.12 \\
\hline 53 & 12 & 0.101 & 299 & NA & 403 & 2982 & $2.24 \mathrm{E}-03$ & $1.99 \mathrm{E}-02$ & 8.85 \\
\hline 54 & 18 & 0.098 & 277 & NA & 309 & 2982 & $2.24 \mathrm{E}-03$ & $2.87 \mathrm{E}-02$ & 12.77 \\
\hline
\end{tabular}

discontinuous increase in surface temperature, to a Point $C$, a condition that clearly must be avoided in a cooling scheme like the one described here. The blue dashed line represents the full boiling curve for a two phase mixture in a setup where the surface temperature can arbitrarily be changed and governs heat transfer rates. While a quantified form of this curve specific to $\mathrm{N}_{2} \mathrm{O}$ is not available, the cooling scheme described here assumes that we can operate between Points $A$ and $B$, thus providing the necessary ratio of heat transfer coefficients. Operation at heat fluxes higher than Point $B$ is expected to cause the rapid failure of the throat, and needs to be avoided.

\section{Summary of results}

The cold side heat transfer coefficient was computed for the 7 test runs results, presented in Table 1 . Runs 53 and 54 had two inlets and outlets so that the overall heat transfer coefficient through the annulus is necessarily higher than in the other runs, and is more representative of the final cooling geometry that will be used in future hardware, i.e., what is targeted for an aerospike. In these two runs the coolant temperature was not measured; the values reported are extracted from run 51 at corresponding locations in the flow. The copper temperature was not measured in run 52; the value reported is extrapolated from run 51 at a station with similar gas temperature. The chamber temperature presented is based on the baseline design condition described above; the actual run condition chamber pressure for runs 48 through 51 was used to correct the baseline data for the hot side heat transfer coefficient; baseline data (200 psia) is used for runs 52,53 and 54 .

Based on the results of the analysis presented above, the ratio of hot to cold heat transfer coefficients varies between 5 and 7.5 for all runs (except for run 48 , where coolant mass flow rate was abnormally low, and the coolant appeared to have completely evaporated in the annulus and potentially decomposed at one point. The ratio in the steady part of that run was 2 ). This matches or exceeds the ratio of 5 described in the section on optimum cooling strategy above. In the runs where two inlets and outlets were used (runs 53 and 54), the ratio is even higher, 9 and 13, respectively, suggesting that the phase mixture of the coolant, on average, is closer to the optimum point. These results thus validate the cooling method proposed here as a feasible means of maintaining throat integrity, from a heat transfer point of view, beyond the minimum heat transfer coefficient ratio defined above, even in the limit of single inlet and outlet coolant paths. With 2 inlets and outlets, the method is demonstrably several times better than required. The two outlet runs (Run 53 and 54) were carried out using the same nozzle, and thus showed that the cooling method can be a suitable means of guaranteeing reusability in nozzle design.

\section{Conclusion}

A research group at Cal Poly has created a small test stand for the study and development of hybrid rocket motors specifically for aerospike applications. One of the key problems in the development of such motors is the dissipation of the high heat loads on the spike. A novel idea, consisting of using the saturated oxidizer of the motor as a coolant was proposed as a means of reducing peak temperature in the hottest part of the flow. The method was implemented on a conventional converging diver ging nozzle, and found to provide sufficient cooling to make the nozzle reusable, and provides a key tool for the development of a reusable aerospike hybrid rocket motor.

\section{Acknowledgments}

The author wishes to thank Professor Thomas W. Carpenter (retired) of the California Polytechnic State University, San Luis Obispo, for providing the original idea of using nitrous oxide as a coolant in hybrid rocket motors, and for sharing my own passion and enthusiasm of gas dynamics. Many thanks also to Professors William Murray and Joseph Mello for developing the test facility and carrying the mechanical design of the rocket motor. James Gerhardt's technical expertise and machining skills were essential in the successful development of all the hardware here. Thank you Jim for your patience and friendship. Thanks to Terry Cooke for keeping the laboratory organized, and for setting up and managing a difficult data acquisition system, and to Lauren Nelson for her dedication to this project. Thanks to the engineers and managers at NASA Dryden who believed in this idea and the future of aerospike nozzles and hybrid rocket motors.

Finally, I would like to recognize and thank Professor Hans G. Hornung for his mentoring, friendship, and advice over the years. You are a true role model. Happy 75 th birthday!

This work was supported by a grant from NASA's Small Business Technology Transfer (STTR) program.

\section{References}

[1] U.S. Air Force photo by Carleton Bailie, 〈http://www.af.mil/weekinphotos/ 030905-08.html >.

[2] Sutton GP, Biblarz O. In: Rocket Propulsion Elements, 7nd ed.. WileyInterscience; 2001. 
[3] T. Bui, et al., "Flight Research of an Aerospike Nozzle Using High Power Solid Rockets", AIAA Paper 2005-3797.

[4] http://sscfreedom.ssc.nasa.gov/esd/ESDPropulsionSS_x33.asp.

[5] M.J., Chiaverini andK.K., Kuo, Eds. Fundamentals of Hybrid Rocket Combustion and Propulsion, 2007, Ch.14.

[6] J.G. Kim, K.J. Lee, S. Seo, Y.M. Han, H.J. Kim, H.S. Choi, "Film Cooling Effects on Wall Heat Flux of a Liquid Propellant Combustion Chamber," AIAA Paper 2006-5196.

[7] E. Martelli, F. Nasuti, M. Onofri, "Thermo-Fluid Dynamics Analysis of Film Cooling in Overexpanded Rocket Nozzles," AIAA Paper 2006-5207.

[8] Y.C. Yu, R.Z. Schuff, W.E. Anderson, "Liquid Film Cooling Using Swirl in Rocket Combustors," AIAA Paper 2004-3360.
[9] Bogard DG, Thole KA. Gas turbine film cooling. Journal of Propulsion and Power 2006; V22(N2).

[10] The idea of using $\mathrm{N}_{2} \mathrm{O}$ as a coolant was originally proposed by Cal Poly Professor T.W. Carpenter (retired) in private communications, 2007.

[11] Bartz DR. A simple equation for rapid estimation of rocket nozzle convective heat transfer coefficient. Jet Propulsion 1957;27(1).

[12] Huzel DK, Huang DH. Modern engineering for design of liquid-propellant rocket engines. AIAA Progress in Astronautics and Aeronautics 1992;147.

[13] S. Gordon, B.J. McBride, Computer Program for Calculation of Complex Chemical Equilibrium Compositions, Rocket Performance, Incident and Reflected Shocks, and Chapman-Jouguet Detonations, NASA SP-273, 1976.

[14] Incropera FP, Dewitt DP, Bergman TL, Lavine AS. In: Fundamentals of Heat and Mass Transfer, $6^{\text {th }}$ Ed.. Wiley; 2007. 